\title{
Testimonial Injustice and Vulnerability: A Qualitative Analysis of Participation in the Court of Protection
}

\author{
Jaime Lindsey
}

\begin{abstract}
This article explores participation in Court of Protection (COP) proceedings by people considered vulnerable. The paper is based on original data obtained from observing COP proceedings and reviewing COP case files. It is argued that the observed absence of the subject of proceedings is a form of testimonial injustice, that is, a failure to value a person in their capacity as a giver of knowledge. The issue of competence to give evidence is considered but it is argued that it is not the formal evidential rules that prohibit a vulnerable adult from giving evidence. Instead, it is the result of a persistent assumption that they are inherently vulnerable and therefore lack credibility as a knowledge giver. This assumption results in the voices of vulnerable adults being routinely absent from legal proceedings. It is argued that having a voice in the courtroom is essential and has a number of intrinsic and instrumental benefits. The paper concludes with a discussion about the implications of the research, including the current trend towards the increased use of special measures, and recommends a presumption in favour of the subject of COP proceedings giving evidence.
\end{abstract}

\section{Key words}

Participation, legal proceedings, Court of Protection, mental capacity, vulnerability, testimonial injustice, evidence

\section{Introduction}

The value of participation has been recognised across a range of legal contexts from criminal to family to human rights law. Involving people in decisions that affect them better respects their autonomy and may alter the outcome. Despite the benefits, a participatory approach has not sufficiently taken hold in mental capacity law. The Mental Capacity Act 2005 (MCA) allows for decisions to be made on behalf of adults where they lack the capacity to make decisions for themselves. Under ss. 2-3 MCA a person may be found to lack capacity to make a decision if they have 'an impairment of, or disturbance in the functioning of, the mind or brain' which means they are unable to understand, retain, or use or weigh the information relevant to the decision, or communicate that decision to others. If a person lacks capacity, a decision can be made on that adult's behalf in their best interests (s 1 (5) and s 4 MCA). The Court of Protection (COP), the court that deals with disputes under the MCA, therefore makes decisions that can have a profound impact on a person's life, ranging from decisions about medical treatment to decisions about where to live and who to marry. The COP even has the power to make a prospective statement that, for example, a person lacks the capacity to engage in sexual activity whereas the criminal law cannot prevent a person from engaging in sex except to the extent they are imprisoned. ${ }^{1}$ Therefore the mental capacity law jurisdiction is an important site of research because of the restrictive interventions that can result. 
There have been discussions around participation under the MCA since it came into force, including analyses of the participatory potential of the best interests approach and the challenges of implementing participation (Donnelly, 2009; ButlerCole and Hobey-Hamsher, 2016; Series et al. 2017). This paper builds on those discussions specifically focusing on the participation of the subject of COP proceedings, referred to as ' $\mathrm{P}$ ', using original data obtained from my observational research at the COP. The subject matter of the cases analysed cover capacity to: consent to sex, marry and decide on contact with others. This is the first published qualitative study of participation in the COP, which is the court that resolves disputes under the civil law framework of the MCA. Historically the COP has been a private court and only recently have the public been granted access, initially via the Court of Protection Practice Direction - Transparency Pilot and a subsequent change in the Court of Protection Rules 2017. This research therefore sheds light on a previously concealed area of practice and provides an original insight into COP proceedings to highlight the injustice of P's limited participation.

The reasons underpinning the value of participation are explored in the first part of this article before the methods used for the research are outlined. Following that, I frame the conceptual approach of the article through a lens of testimonial injustice and vulnerability. Developing the link between testimonial injustice and vulnerability theory, I identify and critique P's absence from proceedings as a form of testimonial injustice, which is the failure to value a person in their 'capacity as a giver of knowledge' (Fricker, 2007: 7). I further explore the reasons why $\mathrm{P}$ is absent from COP proceedings, focusing on the cultural assumption that $\mathrm{P}$ is especially and inherently vulnerable. This culture of the court process frames mentally disabled witnesses as lacking in credibility and as especially harmed by attending court. The article concludes with a discussion about the wider implications of the research, particularly the use of special measures as a way of facilitating participation in legal proceedings. In contributing to this debate, I suggest that the use of special measures alone will do little to improve P's participation in mental capacity law.

\section{The Importance of Participation}

Participation in legal proceedings is an important part of justice. It requires that a person is facilitated to take part in decision-making which affects them (Donnelly and Kilkelly, 2011). Participation does not require that the individual has complete control of the decision-making process. In discussing participation, I am not arguing for an individual's decision-making autonomy to be respected in the substantive sense, because their decision or wishes may ultimately be overruled. However, involving a person in decisions which affect them is still important for intrinsic and instrumental reasons. As procedural justice theorists have established, participation in decisionmaking can have positive effects for the individuals involved and can enhance a person's sense of control over their life, even if the decision does not accord with their wishes (Tyler, 1990; Winick, 1994). This is particularly important in mental capacity law because there is a capacity binary such that individuals are deemed to either have capacity to make a decision or not, whereas a person's understanding is a matter of degree. Even if a person is held to lack capacity to make a decision, she is still likely to have an important contribution to make (Donnelly, 2009: 11-12). Whilst concerns might be raised about the superficial nature of participation should the individual's wishes be ignored, at the very least hearing $\mathrm{P}$ indicates to her that she is a part of the decision-making process. Furthermore, participation must be encouraged 
in a meaningful way, hence the emphasis I place throughout on $\mathrm{P}$ providing sworn evidence.

Involving the person about whom the decision is being made also has instrumental benefits. The decision-making process is improved (Donnelly, 2009) and it may enable the person to engage better with the decision. For example, evidence shows that a person is likely to be less resistant to the outcome if they have been involved in the decision-making process (Dennis and Monahan, 1996). In mental capacity law cases this concern is heightened because the investigation of capacity is often the purpose of proceedings. This means that any assumption of lack of capacity as a reason for P's exclusion violates the principle that capacity must be presumed under s 1 (2) MCA. Furthermore, courts are likely to have a wider range of information on which to base their decision if the person is involved, thereby improving the decision-making process. It is therefore possible that hearing the person at the centre of the case could change the outcome. For instance, $C C v K K$ and STCC [2012] EWHC 2136 concerned an 82 year old woman who lived in a nursing home but wanted to return home to live in her bungalow. Baker $\mathrm{J}$ heard oral evidence from KK and found that she had the capacity to make decisions as to her residence and care, contrary to expert evidence which found that she lacked the capacity to make those decisions. In discussing KK's evidence at para 73 he explained:

Overall, I found in her oral testimony clear evidence that she has a degree of discernment and that she is not simply saying that she wants to go home without thinking about the consequences.

Baker $\mathrm{J}$ repeatedly referred to KK's evidence ${ }^{2}$ and hearing her appeared to make a difference to the outcome. Evidence can be conveyed by others on P's behalf. However, the individual is likely to possess more complete information about their own life because they are most closely situated to it. That is why hearsay evidence is given less weight $-{ }^{3}$ because it is not based on direct knowledge of phenomena. Accurate knowledge cannot be gained without the individual's input and some may lack insight into their own experiences. However, the focus should be on communicating with the individual because they are closer to the truth and without their evidence there is a risk that important information will be omitted. Additionally, if $\mathrm{P}$ is not able to put forward her own knowledge, the evidence of others may be preferred. In fact, this can be seen in cases where the judge has met with $\mathrm{P}$, which have different outcomes from those where the expert evidence alone is relied upon. ${ }^{4}$ In cases such as $C C \vee K K$ and STCC, KK's testimony was given greater weight because Baker $\mathrm{J}$ met with her directly. It is difficult to know what the outcome would have been in the absence of KK's direct evidence, but case law suggests that hearing P's voice has an impact on proceedings.

In some areas, courts have increasingly taken a participatory approach, even for individuals typically characterised as 'vulnerable'. The criminal courts are arguably the most participatory with Brammer and Cooper stating that 'criminal courts are highly likely to hear direct evidence from the child who is the victim of an alleged offence' (2011: 925). Furthermore, it would be highly unusual for a defendant in a criminal case not to be present at hearings and their attendance is fundamentally linked to their Article 6 right to a fair trial under the European Convention on Human Rights (ECHR). Adverse inferences can also be drawn from a defendant's failure to give evidence under s 35 Criminal Justice and Public Order Act 1994. The serious implications for a defendant who wishes to remain silent means that defendants are 
given the opportunity to be heard should they wish to do so. There is much greater emphasis placed by the criminal courts on participation than in the COP even though the implications of findings of incapacity can be just as severe, for example a person who lacks capacity can be deprived of their liberty, prevented from having a sexual relationship or getting married. This reflects the difference in culture between the jurisdictions.

Changes to participation in family law proceedings have been slower to take hold. For example, for some time the consensus appeared to be that children should rarely give evidence in family cases (Brammer and Cooper, 2011). However, this changed following $\operatorname{Re} W$ [2010] UKSC 12, in which Baroness Hale explained at para 22:

The existing law erects a presumption against a child giving evidence... That cannot be reconciled with the approach of the European Court of human Rights... Striking that balance in care proceedings may well mean that the child should not be called to give evidence in the great majority of cases, but that is a result and not a presumption or even a starting point.

Whilst participation is yet to be fully secured in family law, there is a change in court culture taking place towards facilitating participation for vulnerable witnesses. For example, in Wigan Council v M, C, P, GM, G, B and CC [2015] EWFC 8 Jackson J held that whilst expert evidence may be appropriate to determine capability of children to give evidence, it is not always necessary. That decision reinforced the importance of obtaining evidence directly from individuals who are impacted by the decision rather than relying on the evidence or opinion of 'objective' others, such as experts. Balancing expert evidence against evidence from experience may not always be easy. However, having the opportunity to hear evidence from individuals who are directly impacted by the case at least provides the court with a wider range of information and acknowledges the intrinsic value of participation to the individual.

The European Court of Human Rights (ECtHR) similarly explored the value of personal presence in legal proceedings in Shtukaturov v Russia (2012) 54 E.H.R.R. 27, which concerned an adult with a history of mental illness who inherited property from his grandmother. His mother applied to the court seeking to deprive her son of his legal capacity on the basis of a psychiatric report. The district court concluded that the applicant was legally incapable, despite the fact that he was not present for proceedings, was not aware of them and was only informed of the judgment by chance around a year later. The applicant subsequently wished to challenge this decision but was prohibited from having contact with his lawyer. The ECtHR held unanimously that there had been a violation of articles 5(1) and 5(4), 6 and 8. In particular they stated, at para 73:

In such circumstances it was indispensable for the judge to have at least a brief visual contact with the applicant, and preferably to question him. The Court concludes that the decision of the judge to decide the case on the basis of documentary evidence, without seeing or hearing the applicant, was unreasonable and in breach of the principle of adversarial proceedings enshrined in art.6 (1). 
Shtukaturov is not an exceptional case in this context, an observation that will be evidenced throughout. Whilst the COP introduced Rule 3A Court of Protection Rules 2007 (COPr) ${ }^{5}$ which led to $\mathrm{P}$ routinely being joined as a party to proceedings, it remains rare for $\mathrm{P}$ to participate in proceedings in any meaningful way, for example by giving evidence or attending court. Despite improvements to participation in human rights, criminal and family law, it will be shown that P's participation in mental capacity law proceedings has not yet been secured.

\section{Methods}

The data used in this article were obtained from qualitative research carried out at the COP. The research was given approval by the Ministry of Justice to commence in November 2015 and finished in December 2016. The COP research involved two aspects; firstly, observing proceedings relating to eight cases over eleven hearings. Secondly, the research involved a review of a purposive sample of 20 sex/marriage/contact COP case files selected by court staff. From January 2016 staff selected case files that were issued or ongoing and which concerned capacity to consent to sex, capacity to marry and capacity to decide on contact with others. These files were required to be selected by court staff as a condition of the approval. Once the sample limit of 20 was reached in May 2016, no further cases were included. Cases for observation were selected from the sample of 20 case files. The research was approved by the University of Birmingham Research Ethics Committee, the Ministry of Justice and the Vice President of the COP, Mr Justice Charles. The COP staff sent information about the research to all parties in each case observed on my behalf. On the day each judge also gave their approval for me to observe and ensured that participants did not object. Observational research was selected to enable me to become immersed within the culture of proceedings (Jacob, 2012) as well as to explore factors which are often obscured by reported judgments, such as participation, the language used by participants and the set-up of the courtroom. Verbatim notes were made during observations, with additional notes typed up afterwards. Notes were also made from a review of case files, using a case file review template. All data is anonymised throughout.

\section{Testimonial Injustice and P's Vulnerability}

Despite the importance of participation, the data obtained confirm P's routine absence from COP proceedings. Fricker's concept of testimonial injustice gets to the core of this problem; that $\mathrm{P}$ is excluded from the practice of conveying her knowledge (Fricker, 2007). Whilst knowledge can be gained independently of experience, having experience of phenomena can strengthen understanding (Collins and Evans, 2008). Being silenced is the most basic form of testimonial injustice - the inability to communicate your knowledge to another. I use this concept to argue that P's limited participation in COP proceedings is a form of testimonial injustice against her, motivated by concerns about her especial, inherent vulnerability.

Fricker's theory focuses on testimonial injustice caused by prejudice, with such attitudes leading to the speaker's credibility being underestimated; this lack of (or reduced) credibility leads to their knowledge being ignored or devalued (Fricker, 2007). Fricker describes testimonial injustice to be the result of intentional prejudice, rather than of bad luck or 'innocent error' (Fricker, 2007: 21). From my interactions 
with court staff, judges, lawyers and others, most, if not all, did not appear actively prejudiced against $\mathrm{P}$, nor were they motivated by a desire to deny her the opportunity to speak. Those who raised concerns about $\mathrm{P}$ giving evidence primarily expressed it in relation to the detrimental effect that they perceived giving evidence might have on her. This paternalistic attitude appeared to be part of the culture of the COP; that participants assumed that $\mathrm{P}$ needed to be protected for her own good because her disability made her especially vulnerable to the harm of attending court. Such concerns did not typically arise in response to $\mathrm{P}$ giving evidence and having that evidence discounted. Instead she was pre-emptively silenced (Fricker, 2007: 130) as a result of assumptions that mentally disabled people are 'too vulnerable' to participate in legal proceedings.

Concerns about the paternalistic nature of responses under the MCA are clear in judgments ${ }^{6}$ and academic commentaries (Doyle, 2010; Taylor, 2016). Adults with mental disabilities have long been the subject of paternalistic interventions because of their perceived especial vulnerability (Shakespeare, 2006; Clough, 2015). This suggests that those who argue we should be wary of vulnerability discourse might have legitimate concerns. For example, Munro and Scoular have warned the language of vulnerability can be used to justify surveillance and intervention against groups who are labelled 'vulnerable' (Munro and Scoular, 2012). Similarly, it has been argued that the vulnerable/invulnerable dichotomy adopted by law obscures the varied experiences of vulnerability in peoples' lives (Mant and Wallbank, 2017). However, vulnerability has been theorised in recent years in a more nuanced way, particularly by feminist scholars (Fineman, 2008; Fineman; 2010; Clough, 2014; Mackenzie, 2014; Mackenzie et al., 2014). In using the term 'vulnerability' in this article, I adopt an embodied understanding, which takes into account the variety of sources of vulnerability. In this sense vulnerability means being in 'a state of constant possibility of harm' (Fineman, 2008: 11) but also incorporates the possibility that vulnerability varies between individuals and in different situational contexts within an individual's life. In particular, I distinguish between inherent and situational vulnerability (Mackenzie, 2014; Mackenzie et al., 2014; Lindsey, 2016) as a way to refocus legal responses on addressing the embodied vulnerability present in a given case, rather than labelling groups as vulnerable because of their inherent features, such as their disability.

The concepts of inherent and situational vulnerability are also used as a way of framing the different types of vulnerability identified by COP participants (Mackenzie, 2014; Mackenzie et al., 2014). Vulnerability was viewed as inherent in this context because it was perceived to emanate from internal features. In this sense $\mathrm{P}$ was assumed to be inherently vulnerable because of her mental disability, which had two main consequences. Firstly, she rarely had her voice heard or attended proceedings. Secondly, her perceived inherent vulnerability led to her credibility being questioned, both before and after her voice was heard. Yet inherent vulnerability was over-emphasised in contrast to acknowledging the universal vulnerabilities that we all share (Fineman, 2008; Fineman, 2010). This assumption of inherent vulnerability underpins the findings I set out in this article.

The focus on P's inherent vulnerability also highlighted the difference between the especial vulnerability attributed to $\mathrm{P}$, despite that attending court is a vulnerable experience for many people. This concern exemplifies the concept of situational vulnerability that I also use. Situational vulnerability relates to the circumstance-specific causes of vulnerability, such as environmental, social, relational and economic causes. In this context, $\mathrm{P}$ was situationally vulnerable where it was 
Accepted version of article, not to be used or reproduced without author's permission

acknowledged that attending court would be a scary and intimidating experience. However, this form of situational vulnerability was seen as especially harmful to $\mathrm{P}$, whereas the courtroom is likely to be a universally vulnerability inducing experience. I therefore argue throughout this article that by labelling $\mathrm{P}$ as especially vulnerable (inherently and situationally), she was wronged in her capacity as a possessor of knowledge.

\section{Embodiment and Voice in the Court of Protection}

In this section I set out the findings that emerged from the data. I show that $\mathrm{P}$ rarely attended COP proceedings or gave witness evidence. I present this as a form of testimonial injustice, caused by paternalistic attitudes about P's especial inherent vulnerability, which was embedded in the culture of the COP.

\section{Embodiment and Court of Protection proceedings}

The value of having P's embodied presence in COP proceedings should not be underestimated. Firstly, $\mathrm{P}$ has direct experience of her condition and the impact it has on her life. This can be conveyed to the court and other participants through her presence. For example, a person's character and body language can become clearer in their physical presence (Burton et al., 2007: 7). Whereas if COP participants do not engage with mentally disabled adults, if they do not understand the embodied context within which $\mathrm{P}$ lives, their own experience about what constitutes 'normal' embodiment risks becoming normative (Scully, 2012: 140). As a result they may use their own experience as the benchmark from which to judge if they are not faced with the reality of differently embodied people. In the context of mental capacity, this could mean a failure to understand the importance of the provision of support in decision-making as well as a failure to recognise the abilities and life goals that many adults with mental disabilities also have despite their disability. Secondly, a person's presence in the courtroom also reminds participants that there is a person at the heart of the legal case. P's presence can force a cultural shift from an exclusive focus on abstract legal doctrine towards acknowledging the lived reality for those involved in the case and the consequences of their decision on an identifiable individual before them (Fletcher et al., 2008: 323).

Despite the value of embodied presence, P's absence was the most striking theme that emerged from the data. Of the eight cases observed over 11 hearings, $\mathrm{P}$ was present on three occasions. Of the case files reviewed, there was no evidence that $\mathrm{P}$ attended any hearings, gave evidence or spoke to the judge informally. Whilst I did not attend all hearings for each case, it is widely accepted that it is unusual for $\mathrm{P}$ to attend or give evidence in the COP (Butler-Cole and Hobey-Hamsher, 2016; Series et al., 2017). Accordingly I would have expected attendance to be noted in court files.

The COP had attempted to increase P's participation through the enactment of Rule 3A COPr, which makes provision under Practice Direction 2A para 2 to "ensure that in every case the question of what is required to ensure that P's "voice" is properly before the court is addressed'. The primary focus has been on joining $\mathrm{P}$ as a party but Rule 3A (2) (d) COPr also allows for the judge to order that P address her. Similarly, even if $\mathrm{P}$ is deemed to lack competence to give evidence, she can still provide information to the court under COPr 95 (d) and COPr 95 (e). For example, in Re $M$ [2013] EWHC 3456 a District Judge visited P in her care home and made a 
written record of the meeting. However, evidence given in this manner is usually unsworn, limiting its weight, which can have important consequences. For example, in $Y$ County Council v (1) LC (2) GK (3) SC, a case I observed over the course of three hearings and discussed in more detail below, the judge noted that if he did not hear directly from LC then if asked to rely on anything she has said to others, the weight given to such evidence would be small. He also explained that if LC spoke to him in private then 'I won't be able to hear evidence from her'. This suggests that it is in P's interests to give evidence in court otherwise her opinions will be given less weight than those relaying the same information on her behalf. In this respect, there is a need for P's bodily presence in court so that she can provide sworn evidence, which will have the greatest evidential weight. Yet neither rule 3A nor COPr 95 were used to enable P's participation in any cases observed. This was disappointing given that the COP formally appeared to be making progress towards addressing P's limited participation through the enactment of new rules. This highlights that barriers to participation are not always easy to identify (McNay, 2012: 234) because the legal rules are facilitative of P's participation, but instead the obstacles form part of the culture of the court process.

P's absence was striking in $Y$ County Council v (1) $L C$ (2) $G K$ (3) $S C$. The case concerned LC's capacity to marry and consent to sexual relations. LC was a young woman in her early twenties described as having autism and a mild learning disability. LC married a man, GK, without the knowledge of LC's family, despite having a close relationship and living with her mother, SC. There were also ongoing criminal investigations into GK's alleged rape of LC. An application was made to the COP following a safeguarding investigation, which raised concerns about LC lacking the capacity to marry GK, thereby making it 'forced' under s 63A (4) Forced Marriage (Civil Protection) Act 2007. In particular there were concerns that GK married LC to obtain a spousal visa to remain in the UK. In hearing one, counsel for the Official Solicitor, on behalf of LC, explained that there was a letter from LC explaining she did not wish to participate and that she was stressed by proceedings. In hearing two, counsel for the Official Solicitor explained that LC expressed a wish to attend court and speak to the judge but not give evidence. However, the hearing was adjourned and LC's participation was not pursued. At the final hearing counsel for the Official Solicitor indicated that LC would like to see the judge in private 'in order to express her wishes and feelings'. In response the judge explained this was a 'grey area' and that he could not take evidence from LC if he met her in private. Furthermore, on the evidence he had heard, LC might just say whatever was in her head at that time. The judge went on to explain that it is clear from the rules that he should 'encourage, allow and enable' a person who 'hasn't got capacity' to express views to the judge as much as possible. Yet LC did not attend court, nor did she meet with the judge privately. LC was ultimately found to lack capacity to litigate, consent to sex and marry.

LC was not physically present in court despite expressing (through others) a sustained, albeit inconsistent, wish to attend. LC could have explained her understanding of sexual relations, how she experienced them with GK, the voluntariness within which she entered their marriage, and her general wishes and feelings. Furthermore, she could have given an insight into the impact of any court decision on her life. Despite case law requiring that people with disabilities participate in decisions, this has not sufficiently taken hold in the cultural practice of the COP. Whilst rules have been implemented to increase participation, the data obtained 
Accepted version of article, not to be used or reproduced without author's permission

suggests they have so far had limited impact in improving P's embodied presence in sex/marriage/contact cases.

\section{Voice and impaired credibility in Court of Protection proceedings}

In addition to concern over P's limited presence, $\mathrm{P}$ rarely gave witness evidence. There are many aspects of a case for which $\mathrm{P}$ could provide evidence, for example on her wishes and feelings, understanding of specific issues or to enable the judge to gain an overall picture. Every person is assumed to be a competent witness unless they fall within certain categories. ${ }^{7}$ In $A$ County Council v (1) $A B$ (2) $B B$ (3) $C B$ [2016] EWCOP 41 Rogers $J$ affirmed the civil law test for competence to give evidence as whether the witness would understand (a) the solemnity of the occasion and (b) the responsibility to tell the truth. In relation to the solemnity of the occasion, the witness must appreciate the nature and obligation of an oath or affirmation. ${ }^{8}$ In relation to the second part, the court's focus is on whether or not the adult understands the moral duty to speak the truth. However, case law suggests no inquiry is usually made into the understanding of such moral duty, suggesting it is interpreted broadly. ${ }^{9}$ Therefore whilst rules do apply, proving incompetence to testify is a high threshold and in many cases it should not have been difficult to show that $\mathrm{P}$ was competent to give evidence. However, in my observations these rules were not the primary obstacle to $\mathrm{P}$ having a voice. The rules were not expressly discussed and no findings on competence were made in any case observed. Instead, I suggest the culture of the court process led to P's absent voice.

\section{Inherent vulnerability}

A cultural stereotype that mentally disabled adults are especially inherently vulnerable permeated COP proceedings. This stereotype of vulnerability led to P's resulting lack of credibility as a knowledge giver. This cultural understanding of Ps in general was reinforced in specific cases through the language and behaviour of COP participants.

Firstly, the language of inherent vulnerability was prevalent throughout the COP cases observed and case files reviewed. For example, in $C$ Borough Council $v$ (1) DY (2) B Council, the council's position statement stated that DY had an IQ of 47 and a learning difficulty and '[a]s such she is particularly vulnerable and in need of substantial support in all but the most elementary aspects of daily life in order to maintain herself safely.' This shows that DY's vulnerability was linked to her mental functioning (an inherent vulnerability), albeit according to the local authority the matter was before the court because of concerns about an abusive relationship (a situational vulnerability). Similarly, in $O D \vee R$ City Council, the psychiatric report stated that OD 'has no understanding of his disability and vulnerability and need for positive contact and care in either the short or longer term'. The expert further stated '... OD is vulnerable to exploitation, this vulnerability is largely a result of his lack of capacity for sexual relationships...' Again, this related OD's vulnerability back to an internal characteristic. This was reinforced in Y County Council v (1) LC (2) GK (3) $S C$, where LC's vulnerability was mentioned on multiple occasions by participants (in excess of 12 times at the final hearing). It was suggested that LC's naïve, trusting nature, alleged to be the result of her disability, made her vulnerable. The language of 
inherent vulnerability by reference to LC's disabilities was focused upon in contrast to addressing the relationship between LC and GK as the reason for the case being at court. LC was situationally vulnerable within a specific context, to the alleged exploitation by her husband. Yet the legal representatives and judge repeatedly linked her vulnerability back to her disability, highlighting the focus on inherent features.

Secondly, this understanding of inherent vulnerability was present through the framing of expert evidence. For example, psychiatric evidence was taken from Dr Y on LC's capacity to give live evidence. Dr Y was equivocal on LC's capacity, essentially explaining that it would depend how the questions were put to her. Dr Y also explained that 'it's difficult to know her understanding of the truth' and that she would need some evidence to support the fact it's the truth because 'she is too trusting'. She explained that 'most people I see are very worried about court cases' and 'scared about the law' but that 'She [LC] wasn't worried about the court and that it might result in outcomes that she didn't want.' The expert said this 'demonstrated her [LC's] trust in authority'. However, as was suggested by Counsel for LC's husband, her trust in the authority of the court arguably strengthened LC's understanding of the requirement to tell the truth rather than undermined it; she appreciated the importance of giving evidence to a court, which could have lifelong consequences for her.

Dr Y also explained that LC was very keen to please. She explained that girls with autism are keen to fit in and that LC had a tendency to copy others. These descriptions constructed LC as not credible because, as a result of her disability, she was vulnerable to saying anything to fit in. Similarly, LC's social worker explained that LC would often laugh or change the subject. The evidence that LC was likely to change her mind and give different answers came through in the judge's comment that from what he had heard LC might just say whatever is in her head at that time. These comments worked to reduce LC's credibility and attribute it to inherent factors such as her mental disability, pre-emptively silencing her voice. No finding was made about LC's capacity to give evidence and she did not provide oral evidence because, after numerous discussions, her counsel decided not to call her as a witness. This was disappointing given that it was the only case observed which went to a full trial. Most cases never got that far as agreement between the parties was reached outside of court, typically in favour of $\mathrm{P}$ lacking capacity. This shows the value in analysing the data from this case because it was one of the few cases in my sample that reached a full trial. This highlights that it is not formal legal barriers that limit P's participation but the cultural barriers exemplified in the behaviour of the participants.

Thirdly, silencing $\mathrm{P}$, through framing her as especially inherently vulnerable, also resulted from age comparisons with children. The silencing of children is well documented (James et al., 2004; James, 2008: 61; Brammer and Cooper, 2011) and as Murris explains, 'credibility deficit is related to age' (Murris, 2013: 248). Therefore the COP discourse which infantilised adults helped support a generalised opinion that $\mathrm{P}$ was unable to give evidence because she could not be relied upon to be truthful because of her childlike nature. This testimonial injustice led to her voice not being heard. Dr Y gave evidence describing LC as 'very childlike' and that she functions at the age of 7 or 8 . It is concerning that such age comparisons are being made as they only impact negatively on assessments of capacity (Herring, 2010). It is perhaps not surprising that if Dr Y viewed LC as comparable to a child that she concluded LC lacked capacity to consent to sex and marriage. In fact, Dr Y went on to expressly link the two by stating that it was her understanding that it was illegal to have sex with someone who functions at the age of 7 or 8 . Furthermore, reference was made to LC's 
relationship with her teddies in excess of 17 times throughout the final hearing. Whilst on some occasions this was used to highlight flaws in LC's husband's case that he did not realise that LC had a learning disability until some time in to their relationship, at other times it was used to question LC's credibility. This attempt at silencing through infantalisation constructed LC as vulnerable and, as a result, undermined her credibility before she had the opportunity to speak.

Infantilising mentally disabled adults exacerbates their perceived inherent vulnerability resulting in the silencing of their voice. However, Shoemaker gives three important distinctions between mentally disabled adults and children (Shoemaker, 2010). Firstly, mentally disabled adults are physically more mature than children. This will often mean they have had intimate and other relationships, sexual experiences and been able to travel alone. This was the case for LC who had a job, a high degree of independence and was in a sexual relationship. Secondly, the impact of physical and social factors should not be underestimated because they often lead to the adult developing greater emotional maturity as a result of life experience. For example, LC had the experience of a serious adult relationship. Finally, they have greater cognitive maturity than children of a comparable developmental age. This means that because the adult has been at their level of development for a longer time period than children would be (because children move on to the next stage in adolescence) they have experienced that level of functioning on a daily basis for many years. As a result they have a more developed understanding of their own abilities, limits, likes and dislikes than a child would have at such an age. Therefore whilst Dr $\mathrm{Y}$ described LC as comparable to a 7 or 8 year old, this should be an unpersuasive comparison given that a young child would not be able to do the things LC had done according to my observations, such as be in regular employment, travel, attend college and have a sexual relationship. Therefore drawing parallels between the two undermines the important distinctions that law draws between adults and children.

Disabled people have long been understood as especially vulnerable, which has led to the silencing of their voice. This is partly because the logical, rational and predominantly professional voice that dominates legal proceedings is not typical of many people, including those with complex mental disabilities. This is, of course, why legal representation is so essential. However, when the court focuses on the reasons why P's voice should not be heard, 'the law produces the very subjects it claims to protect' (Scott-Hill, 2002: 401). It does so by allowing the evidence to construct $\mathrm{P}$ as inherently vulnerable and therefore unable to give evidence.

\section{Situational vulnerability}

As well as the attribution of vulnerability to inherent factors, there was evidence that those involved in proceedings were concerned that $\mathrm{P}$ was situationally vulnerable, meaning that participants perceived $\mathrm{P}$ to be vulnerable within the courtroom. Whilst situational vulnerability does not automatically relate to P's disability, I suggest that $\mathrm{P}$ was viewed as especially situationally vulnerable in the courtroom, rather than viewing her as situationally vulnerable in the way other witnesses are. Viewing $\mathrm{P}$ in this way led to her exclusion in her capacity as a giver of knowledge.

One case I observed where $\mathrm{P}$ was characterised as situationally vulnerable was $T$ City Council v CY. The case concerned a 49 year old woman's capacity to decide on residence, care and contact. CY was described as having a mild to moderate learning disability and emotionally unstable personality disorder. The case was brought due to concerns about CY's relationship with her partner, SB, and her heavy alcohol 
consumption. It was also noted there were previous concerns about CY being sexually exploited in exchange for alcohol. In addition to the capacity declarations, CY was also subject to a Deprivation of Liberty (DOL) under Schedule A1 MCA. CY objected to being placed under a DOL and was not happy with the restrictions. However, CY's litigation friend accepted the expert evidence that she lacked capacity and the final hearing proceeded with agreement. Unusually, the judge spoke with CY in the courtroom, with her representatives present, but without the other parties (local authority and CY's parents). I was excluded from these discussions before the case commenced, which lasted for approximately five minutes. When CY came out of the courtroom she said that she did not want to go in for the rest of the hearing because the judge is 'going up top now', implying that she did not want to be there when he was sitting in the typical judge's position, in contrast to him sitting at her level during their informal discussion. CY left the building and the other parties and I were invited into court.

On entering court, the judge explained that he understood that $\mathrm{CY}$ was quite frightened so he thought that speaking to her separately would be more appropriate. This is a clear and commendable example of a situational response to her perceived inherent vulnerability. He explained that he kept a note of what she told him and what he asked her. He explained that it was not to be evidence in the formal sense. He did not expand on what he meant by this. On reflection he must have been referring to COPr 95(e). Yet it was not clear that CY lacked competence to give evidence, nor why such informal measures could not have been taken alongside swearing her in and thereby enabling her evidence to be given greater weight. There was also an attendance note in the court file that CY said to her litigation friend that she was frightened of court, but following lots of questions and answers she said 'I'm going to do it, going to go' and 'gave thumbs up' and 'seemed quite enthused'. This suggests that what CY needed, like many others, was reassurance, information and support to facilitate her attendance.

Many reasons for P's limited participation can be attributed to concerns about situational vulnerability. It is well established that giving evidence can be stressful, both for 'vulnerable' people and others (Hunter et al., 2013; Henderson, 2016). That is not to minimise any distress that somebody with a mental disability may additionally experience. Yet Dr Y explained that LC's attitude to the court process was 'frivolous' and that she was a 'robust character' who can 'bounce back from things'. Therefore, it should not be assumed that a person's disability will make the court experience especially more difficult for them. In fact, in some cases $\mathrm{P}$ may experience less anxiety if she has limited experience of the cultural authority of law compared with others. A lack of access to epistemic goods such as education (Fricker, 2013: 1318) is arguably a greater barrier for people with mental disabilities given their poor educational experiences and reduced access to resources. Of course $\mathrm{P}$ is, in many cases, situationally vulnerable; if she does not know what to expect then she may express concerns about attending court. However, situational vulnerability should be addressed in terms that address that specific vulnerability rather than not hearing her voice at all.

\section{Rejection of P's voice and impaired credibility}

Finally, I briefly explore the testimonial injustice that occurred where $\mathrm{P}$ had a voice but it was rejected. Deflated credibility judgements involve rejecting a person's knowledge when it is heard, as well as not hearing it (Wanderer, 2012). So far I have 
set out the reasons why P's voice was absent, primarily because of her perceived especial vulnerability. However, I now consider two cases where P had a voice but her evidence was not viewed as credible, highlighting that voice alone does not guarantee credibility.

I take as a starting point that the subject of a case has a basic level of credibility to speak. That is not to say that P's evidence should always be attributed greater credibility than others, but that most Ps are still likely to have an important contribution to make (Donnelly, 2009: 11-12). This links to wider questions about the balance between expert evidence and evidence from experience, something I do not have the space to explore here. However, mental capacity law proceedings concern individuals who, according to s $1 \mathrm{MCA}$, are assumed to have capacity until there is evidence that they lack it and, under s 4 (6) MCA, weight should be given to P's wishes and feelings even where $\mathrm{P}$ lacks capacity. Therefore, irrespective of how the balance between expert and experiential evidence is resolved in an individual case, it is essential that $\mathrm{P}$ has an opportunity to be heard in relation to decisions which affect her life.

CY's case, discussed in the previous section, is the only case where $\mathrm{P}$ attended the final hearing, therefore giving her a voice and embodied presence. It was not formal witness testimony in that it was unsworn, but it was still 'evidence' as it formed part of the information before the judge. At the start of the hearing, the judge explained that CY told him that she did not like 'DOLS', because she did not like people watching her one to one and she also did not like going out with staff. He also said that she did not understand the reason for the 'DOLS'. CY was asked by counsel why she was at court and she responded that she did not know. The judge explained it was because he would be making a decision about her living arrangements. She was asked if she wanted to stay for the hearing and she said no and then asked to leave, which the judge described as 'understandable'. Despite CY being physically present and having a voice, the judge authorised the DOL against her wishes and declared that she lacked the capacity to litigate and to decide on residence and care. The judge noted that the expert evidence about CY's capacity to decide on contact was 'not sufficient'. I took this to mean that the presumption of capacity under s 1 (2) MCA had not been rebutted. The judge then explained that restricting CY's contact with her partner through her lack of capacity to decide on her care needs 'circumvents the entire problem'. This meant that CY was to be subject to a care plan, which restricted and monitored her contact with SB on the basis that he could not properly care for her, despite her expressed dislike of being watched and the finding that she had capacity to decide on contact.

In another case, $P$ County Council $v$ SE, SE did not have an embodied presence. However, her strong views were put before the court through her representatives. The case concerned an 80 year old woman with dementia who lived in her own home for a number of years with her partner, TM. The COP proceedings started following police attendance at the property, where they raised concerns about SE's living conditions. SE raised no concerns and said she was happy with TM looking after her. SE was subsequently admitted to hospital in a confused and disorientated state. It appeared that SE had not seen her GP for five years although she had some contact with district nurses. SE also had a daughter, LM, who it is said she had not seen for five years as TM did not want LM to go to the flat. The case proceeded as the social workers had concerns about SE's living conditions and TM's ability to provide her with suitable care. There were concerns about TM's mistreatment of SE, although no findings of fact were made. 
Four months prior to the final hearing, SE was moved to a care home, which both SE and TM opposed. In the final hearing the judge held that SE lacked the capacity to make decisions about her care and residence and to manage her property and affairs. However, it was held that SE did not lack capacity to decide on contact or sexual relations. The judge went on to explain that SE's wishes and feelings included her repeated expression of her wish to return home and be cared for by SE. The judge noted that at the time of the final hearing that remained SE's wish. Furthermore, at a meeting between SE, her litigation friend and solicitor, SE was informed that the contents of an independent social work report indicated that it was not feasible for her to return home, to which SE stated 'well I could just die' and made reference to cutting her throat. The judge, in referring to this incident, noted that the solicitor and litigation friend were 'unclear' about SE's wishes and feelings at that point. The judge further explained that the litigation friend had raised concern about SE's deterioration following the last hearing. SE had become immobile, in need of hoisting and feeding by care home staff. In contrast, SE had previously been described as chatty and had had a good sense of humour. Despite SE's clear wishes and feelings being expressed to the court through others the judge held that it was in SE's best interests to remain in the care home.

Despite CY, and to a lesser extent SE, having a voice before the court, neither of their evidence was given sufficient weight to outweigh the other evidence before the court. The importance of providing sworn evidence should therefore not be underestimated in contrast to giving information to the court or having your wishes conveyed by others. However, in CY's case, even if her evidence had been sworn, the cultural stereotype of disabled adults being especially vulnerable and therefore lacking credibility may still have undermined the weight given to her evidence.

\section{Facilitating Participation of Vulnerable Adults}

Finally, I consider ways in which the testimonial injustice identified could be addressed. More recently, the favoured way of securing participation throughout legal proceedings has been through special measures. Special measures are ways of alleviating the anxiety associated with giving evidence, for example through the witness giving evidence through live link. Such measures preserve the weight as evidence will generally be sworn, but attempt to make the experience less stressful. Special measures have been in place in the family and criminal courts for some time (Burton et al., 2007; Brammer and Cooper, 2011) and have been recommended in COP proceedings (Series et al., 2017: 131-132). However, in other contexts there have remained barriers to the use of special measures in practice (Fairclough, 2017). Certain special measures may be more useful than others in the COP. For example, familiarisation visits to court prior to the hearing might be useful in helping to alleviate any fears $\mathrm{P}$ might have and enable them to have their questions answered. Whilst special measures can be useful in addressing the situational vulnerability of the courtroom, I have two concerns with advocating special measures as the solution to this problem.

Witnesses in the COP can give evidence remotely under COPr 98. This is not something I saw used, and one court clerk indicated that live links, when used, are 'not the same'. This articulates my first concern. Using live link means the witness has limited physical presence in court. Yet, as discussed earlier, the interaction between bodies and environment can provide many advantages which may be lost through the giving of evidence remotely. Whilst there is a movement towards court 
digitalisation, the possibility that giving evidence remotely may lack the impact of giving evidence in the courtroom should not be overlooked. As I have emphasised the value of embodiment in this article, solutions that reduce bodily presence need to be carefully considered.

My second concern is that focusing on special measures as the solution here risks reinforcing the assumption that there is something especially vulnerable about $\mathrm{P}$. Whilst special measures can be beneficial, alone they will achieve little to rectify the testimonial injustice towards $\mathrm{P}$ unless special measures are routinely used by a range of different witnesses. This is a similar risk in criminal and family law proceedings as judgements about credibility may also be made about those who use special measures. By advocating special measures as the answer to testimonial injustice, $\mathrm{P}$ may continue to be viewed as especially vulnerable which will continue to impact on her credibility as an evidence-giver.

\section{A rebuttable presumption that $\mathrm{P}$ will give evidence}

I propose that the COPr should be amended to include a rebuttable presumption that $\mathrm{P}$ should give evidence in COP proceedings. This means that it would be assumed that $\mathrm{P}$ would provide evidence unless it was established that she was not competent. For incompetence to testify to be proven, $\mathrm{P}$ would have to be shown not to understand the solemnity of the occasion nor the responsibility to tell the truth. If the COP found she lacked competence, bearing in mind the high threshold, $\mathrm{P}$ would not be able to give sworn evidence. Evidence from a competent $\mathrm{P}$ could be submitted through a witness statement, given orally, or through special measures. This rule change would focus participants on securing P's evidence because it would have to be presumed that she would give evidence. Under this presumption $\mathrm{P}$ would not be compelled to give evidence against her will as her evidence could simply be a statement that she does not wish to be involved.

A central purpose of this rule change is to help challenge persistent attitudes which characterise $\mathrm{P}$ as especially vulnerable and therefore unable to give evidence. Whilst it has been suggested elsewhere that Ps will rarely be competent to give evidence (Charles, 2016; Series et al., 2017), I suggest this assumption is premature. As highlighted above, in no observed case was a determination made about an individual P's competence to give evidence; it was simply assumed. Instead, a clear presumption articulated in the COPr that $\mathrm{P}$ should give evidence would help to challenge the current cultural presumption of incompetence.

A presumption in favour of giving evidence should also result in more situational responses to vulnerabilities identified. For example, if $\mathrm{P}$ expressed a fear of court, this would have to be addressed through special measures rather than excluding P. Some may argue this risks placing P in a stressful situation. However, sworn evidence need not be given in court, despite the embodied benefits of doing so. Furthermore, as emphasised above, $\mathrm{P}$ should not be compelled to give evidence against her wishes. Yet, importantly, any concerns should be addressed through amending the situation within which $\mathrm{P}$ would give evidence rather than assuming she is not competent to do so. In addressing concerns about putting $\mathrm{P}$ in a harmful situation it must be remembered that it is often in P's interests to have her voice heard. An analysis of case law shows that cases where P had a voice and embodied presence, albeit usually by the judge going to meet her, often resulted in P's wishes being respected. ${ }^{10}$ Of course, respecting P's wishes might not always be in P's interests, particularly where there is abuse, as in many cases I observed. However, 
Accepted version of article, not to be used or reproduced without author's permission

from a testimonial injustice perspective, placing P's evidence at the heart of a case is essential. Even if P's evidence does not change the outcome, it is $\mathrm{P}$ who will have to live with the consequences for the rest of her life.

\section{Conclusion}

Using original data I have highlighted P's routine absence from COP proceedings. This is despite moves under the ECHR and other jurisdictions to facilitate participation. I have framed P's absence as a form of testimonial injustice underpinned by attitudes which view mentally disabled adults as especially vulnerable. Whilst I have no doubt that, in some cases, P can be described as vulnerable, the cultural stereotype of inherent vulnerability is concerning. Furthermore, attributing P's vulnerability to the existence of a mental disorder rather than her situational context works to culturally exclude P from proceedings and limits her participation in decision-making. Such attitudes undermine P's credibility in the exceptional cases where she does give evidence.

There remain barriers to meaningful participation, including the culture of the court, judicial and professional attitudes and the court set-up. I briefly explored the role that special measures might play in addressing these barriers. Further research is undoubtedly needed to investigate the impact on the perception of evidence when special measures are used. In particular, the use of special measures that exclude P's physical presence in court raise concerns and require a stronger evidence base before they are routinely advocated. Whatever the solutions adopted, it is a matter of justice that Ps are given the opportunity to participate in COP proceedings and have their knowledge heard. The COP makes decisions that will fundamentally impact on P's life and therefore, intrinsically and instrumentally, there is enormous value in $\mathrm{P}$ having her own voice and bodily presence before the court.

\section{Acknowledgements}

The author would like to thank Marie Fox, Rosie Harding, Maurice Sunkin and Sabine Michalowski for their feedback on earlier drafts, as well as the anonymous reviewers and the editors for their extremely helpful comments.

\section{References}

Brammer A and Cooper P. (2011) Still waiting for a meeting of minds: child witnesses in the criminal and family justice systems. Criminal Law Review: 925-942.

British Psychological Society. (2017). Available at: https://careers.bps.org.uk/area/clinical (Accessed: 15 June 2017).

Burton M, Evans, R and Sanders, A. (2007) Vulnerable and intimidated witnesses and the adversarial process in England and Wales. International Journal of Evidence and Proof 11: 1-23.

Butler-Cole V and Hobey-Hamsher L. (2016) The Assessment of Capacity by Judges of the Court of Protection. Elder law Journal 6: 145-151.

Charles J. (2016) Facilitating participation of ' $P$ ' and vulnerable persons in Court of Protection

proceedings. http://www.familylaw.co.uk/system/froala_assets/documents/1334/Practice_G uidance_Vulnerable_Persons.pdf (Accessed: 12 November 2017). 
Accepted version of article, not to be used or reproduced without author's permission

Clough, B. (2014) Vulnerability and capacity to consent to sex - asking the right questions? Child and Family Law Quarterly 26: 371-397.

Clough B. (2015) 'People like that': realising the social model in mental capacity jurisprudence. Medical Law Review 23: 53-80.

Collins H and Evans R. (2008) Rethinking Expertise, Chicago: University of Chicago Press.

Dennis D and Monahan J. (1996) Coercion and Aggressive Community Treatment: A New Frontier in Mental Health Law. New York: Plenum Press.

Donnelly M. (2009) Best Interests, Patient Participation and The Mental Capacity Act 2005. Medical Law Review 17: 1-29.

Donnelly M and Kilkelly U. (2011) Child-friendly Healthcare: Delivering on the Right to be Heard. Medical Law Review 19: 27-54.

Doyle S. (2010) The Notion of Consent to Sexual Activity for Persons with Mental Disabilities. Liverpool Law Review 31: 111-135.

Fairclough S. (2017) 'It doesn't happen ... and I've never thought it was necessary for it to happen': Barriers to vulnerable defendants giving evidence by live link in Crown Court trials. The International Journal of Evidence \& Proof 21: 209229.

Fineman MA. (2008) The Vulnerable Subject: Anchoring Equality in the Human Condition. Yale Journal of Law and Feminism 20: 1-23.

Fineman MA. (2010) The Vulnerable Subject and the Responsive State. Emory Law Journal 60: 251-276.

Fletcher R, Fox M and McCandless J. (2008) Legal embodiment: analysing the body of healthcare law. Medical Law Review 16: 321-345.

Fricker M. (2007) Epistemic Injustice: Power and the Ethics of Knowing, Oxford: Oxford University Press.

Fricker M. (2013) Epistemic justice as a condition of political freedom? Synthese 190: 1317-1332.

Henderson E. (2016) Taking control of cross-examination: judges, advocates and intermediaries discuss judicial management of the cross-examination of vulnerable people. Criminal Law Review: 181-205.

Herring J. (2010) Commentary on: Sheffield City Council v E. In: Hunter R, McGlynn $\mathrm{C}$ and Rackley E (eds) Feminist Judgements; From Theory to Practice. Online: Hart, 346-352.

Hunter G, Jacobson J and Kirby A. (2013) Out of the shadows: victims' and witnesses' experiences of attending the Crown Court. London.

Jacob M-A. (2012) Matching Organs with Donors: Legality and Kinship in Transplants, Philadelphia: University of Pennsylvania Press.

James AL. (2008) Children, the UNCRC, and family law in England and Wales. Family Court Review 46: 53-64.

James AL, James A and McNamee S. (2004) Turn down the Volume Not Hearing Children in Family Proceedings. Child and Family Law Quarterly 16: 189202.

Lindsey J. (2016) Developing Vulnerability: A Situational Response to the Abuse of Women with Mental Disabilities. Feminist Legal Studies 24: 295-314.

Mackenzie C. (2014) The Importance of Relational Autonomy and Capabilities for an Ethics of Vulnerability. In: Mackenzie C, Rogers W and Dodds S (eds) Vulnerability: New essays in ethics and feminist philosophy. New York: Oxford University Press, 33-59. 
Accepted version of article, not to be used or reproduced without author's permission

Mackenzie C, Rogers W and Dodds S. (2014) Introduction: What Is Vulnerability and Why Does It Matter for Moral Theory? In: Mackenzie C, Rogers W and Dodds S (eds) Vulnerability: New Essays in Ethics and Feminist Philosophy. New York: Oxford University Press, 1-29.

Mant J and Wallbank J. (2017) The Mysterious Case of Disappearing Family Law and the Shrinking Vulnerable Subject: The Shifting Sands of Family Law's Jurisdiction. Social \& Legal Studies 26: 629 - 648.

McNay L. (2012) Suffering, Silence and Social Weightlessness: Honneth and Bourdieu on Embodiment and Power. In: Gonzalez-Arnal S, Jagger G and Lennon K (eds) Embodied Selves. Hmapshire: Palgrave Macmillan, 230-248.

Munro VE and Scoular J. (2012) Abusing Vulnerability? Contemporary Law and Policy Responses to Sex Work in the UK. Feminist Legal Studies 20: 189-206.

Murris K. (2013) The Epistemic Challenge of Hearing Child's Voice. Studies in Philosophy and Education 32: 245-259.

Scott-Hill M. (2002) Policy, politics and the silencing of 'voice'. Policy \& Politics 30: 397-409.

Scully JL. (2012) Disability and the Thinking Body. In: Gonzalez-Arnal S, Jagger G and Lennon K (eds) Embodied Selves Hampshire: Palgrave Macmillan, 139159.

Series L, Fennell P and Doughty J. (2017) The Participation of P in Welfare Cases in the Court of Protection. Cardiff: Cardiff University.

Shakespeare T. (2006) Disability Rights and Wrongs, Abingdon: Routledge.

Shoemaker D. (2010) Responsibility, Agency, and Cognitive Disability In: Kittay EF and Carlson L (eds) Cognitive Disability and its Challenge to Moral Philosophy Chichester: Wiley-Blackwell, 201-223.

Taylor HJ. (2016) What are 'Best Interests'? A critical evaluation of 'Best Interests' decision-making in clinical practice. Medical Law Review 24: 176-205.

Tyler T. (1990) Why People Obey the Law, New Haven: Yale University Press.

Wanderer J. (2012) Addressing Testimonial Injustice: Being Ignored and Being Rejected. The Philosophical Quarterly 62: 148-169.

Winick BJ. (1994) The Right to Refuse Mental Health Treatment: A Therapeutic Jurisprudence Analysis. International Journal of Law and Psychiatry 17: 99117.

\footnotetext{
${ }^{1}$ Or also possibly if the offender was subject to a sexual prevention order under s 104 (2) Sexual Offences Act 2003.

${ }^{2}$ paras $64,65,69,70,73$.

${ }^{3}$ Enfield LBC $v$ SA [2010] EWHC 196.

${ }^{4} C C v$ KK and STCC [2012] EWHC 2136, Re M [2013] EWHC 3456, A Local Authority v TZ [2013] EWCOP 2322, Xv A Local Authority and Another [2014] EWCOP 29, Wye Valley NHS Trust $v$ B [2015] EWCOP 60, Re Z [2016] EWCOP 4.

${ }^{5}$ This paper refers to the 2007 rules as these were in force at the time the data was obtained.

${ }^{6}$ In re A (Capacity: Refusal of Contraception) [2010] EWHC 1549 para 61, IM v (1) LM (2) AB (3) Liverpool City Council [2014] EWCA Civ 37 paras 1, 42, 82.

${ }^{7}$ Halsbury's Laws $\left(5^{\text {th }}\right.$ edn, 2015) vol 12, para 793.

${ }^{8} R v$ Wade (1825) 1 Mood CC 86, $R$ v Samuel Hill (1851) 169 E.R. 495 and Spittle $v$ Walton [1870]

L.R. 11 Eq. 420.

${ }^{9}$ Ibid.

${ }^{10} \mathrm{n} 4$ above.
} 